\title{
Modelos de ação profissional de professores de Educação Física de uma escola profissionalizante
}

\author{
José Ângelo Gariglio*
}

\begin{abstract}
Resumo: O trabalho relata alguns dos resultados de um estudo realizado com professores de Educação Física de uma Escola Profissionalizante. Mais especificamente, versa sobre o conjunto das percepções que docentes de Educação Física de uma Escola Profissionalizante têm sobre o seu trabalho docente na escola, a partir de modelos de estruturação da ação profissional, edificados dentro de um campo disciplinar específico: a Educação Física. Conclui mostrando que a prática pedagógica em EF na escola é detentora de uma natureza singular, produtora de um conjunto de representações singulares acerca do papel da EF e de seus professores, representações essas que servem para definir, estruturar e orientar a atuação desses docentes em situações de ação.
\end{abstract}

Palavras-chave: Educação Física. Docentes. Prática profissional.

\section{A ORIGEM DO PROBLEMA DE PESQUISA}

Este texto relata os resultados de uma pesquisa feita com três professores de Educação Física (EF) de uma escola profissionalizante. ${ }^{1}$ Este estudo buscou compreender quais modelos de ação profissional ${ }^{2}$ serviriam de guia para intervenção desses docentes na escola. Por meio da análise do discurso de professores de EF, tentamos delinear algumas das especificidades educacionais que seriam definidoras do papel pedagógico da EF e desses profissionais de ensino, em contraste com os demais professores da instituição.

\footnotetext{
* Bacharel e Licenciado em Educação Física. Mestre e Doutor em Educação. Professor do Centro Federal de Educação Tecnológica de Minas Gerais, Belo Horizonte, MG, Brasil. E-mail: angelogariglio@hotmail.com

${ }^{1}$ A instituição é o Centro Federal de Educação Tecnológica de Ouro Preto - CEFET-OP

${ }^{2}$ Os modelos de ação são as representações elaboradas e veiculadas pelos professores a respeito da natureza de sua prática, representações essas que servem para defini-la, estruturála e orientá-la em situações de ação (TARDIF, 2002).
} 
Tendo essa questão como o centro de interesse da pesquisa, duas orientações teóricas apresentaram-se como fundamentais na organização da nossa reflexão: a primeira é que cada disciplina escolar ostenta o seu princípio de inteligibilidade, seu paradigma - sua matriz disciplinar que organiza a totalidade dos conteúdos num conjunto coerente. O paradigma disciplinar é fundamental porque ele determina as tarefas que serão desenvolvidas com os alunos, os conhecimentos declarativos a ensinar e os conhecimentos procedimentais correspondentes (DEVALY, 1995; SHULMAN, 1986; SHULMAN, 1987).

A segunda é que as disciplinas escolares são entidades culturais dotadas de características sui generis, que, longe de ser mero reflexo de disciplinas científicas e acadêmicas, constituem-se campos de ação fortemente marcados pelas contingências de tempo e espaço escolar, pelas cláusulas explícitas dos contratos pedagógicos e didáticos, pelas estratégias de ensino voltadas aos alunos, pelas exigências dos colegas, pelas necessidades imediatas da vida institucional e pelos sistemas de avaliação e seleção. Nesse sentido, uma disciplina escolar apresenta-se como um conjunto de saberes, de competências, de posturas físicas e/ou intelectuais, de atitudes, de valores, de códigos e de práticas que trazem as marcas da forma escolar (CHERVELL, 1998).

Nessa linha reflexiva, algumas questões emergiram como centrais para a condução do nosso percurso investigativo, a ver:

- as disciplinas escolares haveriam de se constituir em elemento informador e organizador do processo de construção dos saberes profissionais dos professores? Se elas se definem como entidade cultural destinada não somente à instrução, mas também à socialização dos alunos, elas não o seriam também para os professores? De que forma elas contribuem para calçar o processo de constituição dos saberes da prática profissional desses docentes?

\section{SABER DOCENTE COMO UMA PRODUÇÃO SOCIAL: UM SABER INTERATIVO}

Apesar de verificarmos que no Brasil os estudos sobre saberes da base profissional dos professores precisam, ainda, alargar suas 
fronteiras de investigação, em algumas partes do mundo - em especial nos EUA e no Canadá -, esses estudos encontram-se num estágio mais avançado. Nos últimos 20 anos, a pesquisa sobre os saberes da base profissional de docentes da educação básica vem não somente crescendo, mas também diversificando-se em linhas orientadas por modelos teóricos os mais diversos.

O acúmulo teórico sobre o tema dos saberes e conhecimentos dos professores acabou por gerar uma base suficiente de trabalhos que possibilitaram alguns autores a produzir sínteses, com o objetivo de captar as diversidades teóricas e metodológicas de pesquisa, a fim de estabelecer, segundo critérios específicos, determinados agrupamentos, classificações e tipologias (BORGES, 2001).

No nosso estudo, faremos uso de uma tipologia produzida por Tardif (2000). O autor buscou construir uma síntese que pudesse agrupar em blocos visões diferenciadas de estudos que procuram caracterizar a subjetividade dos professores.

Conforme a tipologia criada por esse autor, os trabalhos que levam em consideração a subjetividade dos professores seriam desenvolvidos com base em três grandes orientações teóricas. A primeira delas define as pesquisas no âmbito da cognição ou do pensamento dos professores; essas pesquisas, de inspiração psicológica, fazem parte da corrente das ciências cognitivas, especialmente da psicologia cognitiva. De maneira geral, essa primeira orientação teórica é dominada por uma visão cognitivista e psicologizante da subjetividade dos professores. Procura, com frequência, definir as características cognitivas do professor perito, do professor eficiente e propõe uma visão bastante racionalista do professor, reduzindo a sua subjetividade à sua cognição, cognição essa concebida segundo uma visão intelectualista e instrumental.

A segunda orientação teórica define as pesquisas como o que se pode chamar de vida dos professores. Tais pesquisas baseiam-se em diversas correntes teóricas, como a fenomenologia existencial, a história de vida pessoal e profissional, os estudos sobre as crenças dos professores e os enfoques narrativos que estudam a sua voz. Nessa segunda orientação, a subjetividade dos professores é vista 
de maneira mais ampla do que na primeira, já que não se limita à cognição ou às representações mentais, mas engloba toda a história de vida dos professores, suas experiências familiares e escolares anteriores, sua afetividade e emoção, suas crenças e valores pessoais.

A terceira orientação teórica baseia-se em enfoques que vêm sendo propostos no campo da sociologia dos atores e da sociologia da ação: interacionismo simbólico, etnometodologia, estudo da linguagem comum ou cotidiana, pesquisa sobre as competências sociais dos atores. Nessa terceira orientação, a subjetividade dos professores não se reduz à cognição ou à vivência pessoal, mas remete às categorias, regras e linguagens sociais que estruturam a experiência dos atores nos processos de comunicação e de interação cotidiana. $\mathrm{O}$ pensamento, as competências e os saberes dos professores não são vistos aqui como realidades estritamente subjetivas, porque são socialmente construídos e partilhados.

Tomando essa classificação como organizadora do quadro teórico que vem orientando boa parte das pesquisas sobre os saberes docentes atualmente em todo o mundo, destacamos que a concepção de saber docente, com a qual trabalhamos no nosso estudo, está predominantemente amarrada à terceira orientação teórica, sem desconsiderar, no entanto, as outras duas orientações, naquilo que podem oferecer de subsídios para a investigação da produção dos saberes dos professores de EF investigados.

Segundo essa concepção, dizer que um professor sabe ensinar não é somente avaliar uma perícia subjetiva fundada em competências profissionais, mas é, ao mesmo tempo, emitir um juízo social e normativo em relação a regras e normas, a jogos de linguagem que definem a natureza social da competência dos professores dentro da escola e da sociedade (TARDIF, 2000; GAUTHIER et al., 1998).

Pensar o saber docente como uma produção social dos professores requer lembrar algumas premissas fundamentais: primeiro, seus conhecimentos são construídos dentro de um quadro de constrangimentos que orientam e demarcam as possibilidades e os limites de atuação profissional dos docentes. Ela guarda, assim, forte teor estatutário e codificado, no qual os aspectos de normatização e 
institucionalização do trabalho apresentam-se como ativos organizadores da atividade docente. Segundo, os saberes dos professores são construções adquiridas por meio de práticas interativas e partilhadas. Elas colocam em presença, ombro a ombro, os diversos agentes escolares (alunos, professores, pais), exigindo que os docentes construam suas habilidades pedagógicas em franca interação com esses atores, negociando papéis mútuos, de acordo com perspectivas mútuas. Terceiro, o saber docente é social porque é adquirido, principalmente, no contexto de uma socialização profissional, em que é incorporado, modificado, adaptado em função dos momentos e das fases de uma carreira, ao longo de uma história profissional na qual o professor aprende a ensinar fazendo o seu trabalho. Se parte significativa da constituição dos saberes docentes é forjada nas experiências coletivas vividas pelos professores na trajetória como estudante da educação básica, nos cursos de licenciatura e no desenvolvimento das ações profissionais na escola, há que se considerar que parte significativa dessas experiências são materializadas dentro de um campo disciplinar. Como ressalta Borges (2002), a profissão docente no Brasil sofreu e sofre uma forte orientação disciplinar, tornando-se constituinte dos saberes profissionais, particularmente na identificação com a matéria, na mirada sobre o ensino, na forma como definem-se como os professores de uma disciplina.

A análise das situações de trabalho coletivo, as relações estabelecidas pelos professores com organização social da escola, o trabalho docente nas ações de gestão da sala de aula e do conhecimento precisam, a nosso ver, ser atualizadas em função dos ordenamentos epistemológicos e pedagógicos próprios de cada campo e/ou as disciplinas escolares. Para isso, pareceu-nos importante levantar algumas das características constituidoras dos modelos de ação pedagógica de professores de Educação Física.

\section{A TRAJETÓRIA MERCADOLÓGICA}

Com essas e outras questões, lançamo-nos ao campo de pesquisa, com o intuito de investigar a prática profissional de três profes- 
sores de EF, dois homens e uma mulher, pertencentes ao quadro de docentes de uma escola profissionalizante da rede federal de ensino. ${ }^{3}$

Os três docentes investigados não foram escolhidos de maneira aleatória. A escolha foi submetida aos seguintes critérios: ter formação superior, ter mais de dez anos de experiência profissional na área da $\mathrm{EF}$, ter mais de cinco anos de experiência profissional na escola pesquisada, estar submetido ao regime contratual de dedicação exclusiva e pertencer ao quadro efetivo da escola, ou seja, deter estabilidade no emprego.

Levamos em consideração aqui a classificação desenvolvida por Huberman (1992) sobre o ciclo de vida profissional de professores. Como nosso objeto de estudo centra seu foco de análise nos saberes que são construídos pelos professores em função dos desafios colocados pela sua prática profissional, entendemos que deveríamos trabalhar com professores experientes. Nessa direção, os professores pesquisados estão enquadrados dentro da fase do ciclo profissional que Huberman denomina de diversificação. Nessa fase, os professores se lançariam a uma série de experiências profissionais, diversificando o material didático, o modo de avaliação, a forma de agrupar os alunos e as sequências do programa.

Partimos, também, do entendimento de que os saberes docentes são produções interativas, construídos na relação com os demais atores da escola e mediados pelo conjunto de regras e normas da vida institucional. Com isso, fez-se necessária a utilização de várias fontes de informação, observação e análise da realidade. Associadas às técnicas de observação direta das aulas de Educação Física, foram utilizadas, ainda, a entrevista e a análise de documentos produzidos pelos docentes. Com tais estratégias, buscamos comparar relatos distintos, confrontar posições de diferentes sujeitos sobre o mesmo tema e verificar contradições entre práticas e discursos.

Com isso, buscamos identificar o conjunto das representações pedagógicas construídas pelos professores de EF, ou melhor, o conjunto de discursos, símbolos, sentimentos e comportamentos, normas, prescrições

${ }^{1}$ A pesquisa foi realizada durante todo o ano letivo de 2002. 
que contribuiriam para a confirmação dos próprios docentes de sua própria capacidade de ensinar.

\section{A EXPERIÊNCIA ESCOLAR DE PROFESSORES DE EF E ALGUNS DE SEUS MODELOS DE AÇÃO PROFISSIONAL}

Vamos tentar identificar, por meio do discurso de professores de EF, como eles situam as especificidades educacionais que seriam definidoras do papel pedagógico da $\mathrm{EF}$ e, por via de consequência, desses profissionais de ensino, em contraste com os demais professores da instituição. Quais seriam os modelos de ação profissional orientadores da prática profissional desses docentes na escola? Sobre essa questão é importante sublinhar que parte do papel pedagógico atribuído à EF pela escola e pelos seus professores tem relações com as singularidades do estabelecimento escolar onde a investigação foi realizada: uma escola profissionalizante.

Dentre os diferentes contextos que constituem a prática docente de nossos professores, pudemos verificar que, quando eles falam das funções e das especificidades da intervenção pedagógica que cabem à EF, invariavelmente relacionam a sua disciplina ao potencial que ela teria de poder intervir na formação de valores, na socialização, ou seja, na formação geral dos alunos. Estes relatos mostram um pouco essa tendência:

Por exemplo, se a turma tem um problema de relacionamento, vou usar o que eu tenho para lidar com isso, porque é um espaço com o qual a Educação Física tem o privilégio de trabalhar. Não é geral, mas existem professores que têm essa preocupação fora do seu campo, da disciplina específica, mas a maioria está ali muito enfocada na sua própria disciplina. E acho que grande parte, não todos, lá na área dá conta desse olhar mais amplo. (Prof ${ }^{a}$. Márcia)

$[\ldots]$

A questão do relacionamento, a questão da afetividade é bem aberta, a proximidade das relações; eu não abro mão disso, de jeito nenhum. (Prof. Leandro)

Vovimento, Porto Alegre, v. 16, n. 02, p. 165-191,abril/junho de 2010. 
Vemos que os nossos professores se esforçam em dizer que as práticas de ensino que definem a especificidade de intervenção pedagógica da EF não se limitam à transmissão de seus conteúdos. A Prof $^{a}$ Márcia, ao operar uma comparação entre a prática pedagógica dos professores de EF e os docentes das demais disciplinas, salienta que os outros professores ficam restritos e enfocados na sua própria disciplina, enquanto os de EF dariam conta de um olhar mais amplo.

A nosso ver, essa amplitude de olhar do qual nos fala a Prof ${ }^{a}$ Márcia parece relacionar-se com certo potencial ou sensibilidade pedagógica para saber como intervir na formação dos estudantes para além da sua dimensão epistêmica. Em função do território de atuação que caberia à EF na escola, ou seja, o de intervir na formação do saber-ser, os professores entendem que eles seriam mais atentos, por exemplo, às formas de construção das relações coletivas operadas pelos alunos. Paralelamente, essa necessidade de ter um olhar mais amplo parece estar relacionada à capacidade de saber ver os alunos para além dos resultados escolares. Seria preciso desenvolver canais de verificação e comunicação com a ordem subjetiva dos alunos, isto é, com suas emoções, seu comportamento e sua forma de significação do mundo.

Também, ao relatar uma experiência construída por um professor de Matemática dentro da escola, quando ele se lança a uma experiência de ensino fora da sala de aula tradicional, ou seja, no interior do pátio da escola, ela busca mostrar e demarcar quais seriam as diferenças entre o papel da EF e o de seus professores diante das outras disciplinas:

Um professor de Matemática, uma vez pediu uma quadra, eu fui até assistir a atividade dele; ele estava ensinando figuras geométricas. Foi muito interessante, mas em nenhum momento ele estava preocupado com o relacionamento dos alunos, e sim em ensinar as figuras geométricas e a relação entre base, altura, não sei o quê e espaço, essas coisas. (Prof ${ }^{\mathrm{a}}$. Márcia).

Na mesma perspectiva, o Prof. Mauro nos mostra que a EF não se enquadraria no campo das disciplinas tidas como acadêmicas. A 
sua definição de disciplinas acadêmicas parece estar atrelada a aprendizagens mais racionais, intelectualizadas por meio do contato com conhecimentos mais abstratos e distantes das relações humanas mais concretas:

Porque eu tenho a clareza de que é uma disciplina que no contexto acadêmico ajuda na formação geral desse aluno. Quebra um pouco a formação acadêmica e traz uma outra vertente que é tão ou mais importante que a outra. Acho que esse papel é nosso, falei sobre isso antes da construção das relações entre eles em função do limite, da expressão corporal, da abertura para xingar, para falar palavrão, e depois você falar, porque você está lidando com aquilo, então esse é um papel. Ela estará contribuindo para sair do contexto informal. A formal eu estou falando, Português, Matemática, que é a formação acadêmica, e a outra é a educação para a vida, de ser educado, de ter o seu limite, de respeitar o colega, de se relacionar bem com ele. Porque ela ajuda nessas disciplinas da sala de aula. (Prof. Mauro).

Nesses relatos, fica novamente evidente que o que demarcaria a especificidade e o papel pedagógico da EF e da ação docente nessa disciplina seria aquele de oferecer aos discentes práticas de ensino, vivências educativas e a transmissão de conteúdos capazes de ir além da formação tida como acadêmica. Seria própria da EF a intensificação de processos formativos que alcançassem os conteúdos da formação humana necessários à vida em comum. Vale, no entanto, questionar se as outras disciplinas da escola também não cumpririam esse papel. Entendemos que isso não é privilégio da EF. Em contrapartida, o que os professores parecem tentar nos dizer é que, em função do conhecimento que ensinam e do lugar pedagógico ocupado pela EF na escola, eles encontrariam maior comodidade para o tratamento de questões que envolvem mais diretamente temas como a sociabilidade e a educação estética.

Para além disso, o relato do Prof. Mauro parece nos informar-nos que a EF situar-se-ia dentro do universo de atividades mais ligadas aos setores de apoio ao ensino, disponibilizados pela escola (supervisão educacional, apoio psicológico, atendimento médico e serviço social) ou, 
como também destaca o jornal da própria instituição, uma disciplina construtora do "cenário de uma boa recepção à aprendizagem". A EF, na visão desse professor, ofereceria aos alunos experiências educativas que seriam significativas para que eles pudessem ter melhor conduta dentro da sala de aula. Poder propiciar aos alunos momentos de formação cunhados em situações mais informais produziria uma quebra da rotina da escola, o que seria benéfico para a conduta dos alunos na ocasião em que o ensino se faz mais formal.

A perspectiva apontada pelos professores Mauro e Leandro parece ser complementada pela docente Márcia, quando ela, a todo o momento, ressalta que o que caracterizaria o tipo de relação pedagógica dentro do universo de ensino específico da EF seria uma relação mais informal, afetiva e aberta com os alunos, a produção de um espaço pedagógico em que existiria a possibilidade do diálogo, das discussões e de uma intimidade maior nas relações intersubjetivas de alunos/alunos e professores/alunos. No relato seguinte, Márcia mostra que esse tipo de conduta e abertura do professor seria uma pré-condição para que as práticas de ensino em EF tivessem o efeito esperado:

É a relação mesmo, a coisa mais aberta, mais fraterna, o toque. De uma maneira mais livre, mais ampla, aberta a discussões, à construção coletiva, o espaço mais aberto para negociações. É justamente desse detalhe de relação, de construir junto, de cooperar, de que ninguém faz nada sozinho, que, por menor que seja a contribuição de um elemento para o coletivo, para o grupo, ela tem que ser ouvida, saber ouvir. A questão do relacionamento, a questão da afetividade é bem aberta, a proximidade das relações; e eu não abro mão disso, de jeito nenhum. (Prof ${ }^{\mathrm{a}}$. Márcia)

Esse relato também pode-nos revelar que, para os professores de EF, a presença da dimensão afetiva tornar-se-ia um dos elementos diferenciadores não somente da prática educativa em EF, mas da sua própria capacidade de ensinar. Essa constatação contrasta com as conclusões dos estudos efetuados por Lessard et al. (2003) sobre a constituição de culturas docentes diferenciadas de professores que militam no Ensino Médio e no Ensino Fundamental. Apesar de 
estarmos lidando com professores de EF que atuam no nível médio, esses não se encaixam na descrição da cultura docente própria dos professores desse nível escolar. A dimensão afetiva e maternal que seria própria da cultura docente de professores da educação infantil e do Ensino Fundamental mostra-se presente e fundante para a prática pedagógica dos professores de EF aqui pesquisados.

Essa visão é reforçada pelo professor Mauro, quando esse descreve como vê os seus alunos e o tipo de relação com eles estabelecida:

É quase como se fossem meus filhos. Eu não consigo estar lidando com eles como pessoas por ser minha obrigação como profissional, eu não consigo lidar com eles dessa forma e esquecê-los. Não é paternalismo, mas é de responsabilidade, tanto quanto teria o pai nesse processo, por conta da minha visão de mundo, da minha expectativa de vida, de uma percepção social, violência e uma série de outras coisas, o interesse, o quanto me faz bem do ponto de vista pessoal a minha relação com a escola, o meu trabalho, o quanto eles podem se dar bem também com isso de tratar os outros com respeito, com carinho, com educação, de ser gentis, saber agradecer, saber pedir licença, abrir uma porta. Não estou dizendo que os pais não façam isso, quem sou eu para dizer isso. Mas é isso que eu acho que a gente pode estar ajudando. Nesse contexto todo, só consigo concebê-los como filhos mesmo, com essa responsabilidade nessa construção. (Prof. Mauro).

É interessante percebermos que os professores, apesar de serem do sexo masculino e ministrarem aulas no nível médio, não exitam em manifestar como centrais no seu trabalho determinadas dimensões presentes na prática docente que são pouco valorizadas em meios profissionais onde os homens são a maioria e o profissionalismo mostra-se incompatível com o envolvimento afetivo. Há, no discurso dos nossos professores, o que Carvalho (1998) denomina cultura do cuidado. Essa cultura do cuidado foi muitas vezes tomada como reiteração dos papéis e características consideradas adequadas à feminilidade ou vistas como intrínsecas a uma docência considerada adequada às séries iniciais. 
O que o professor tenta mostrar é que a presença da afetividade ou da cultura do cuidado não se encontra represada no universo da docência feminina ou mesmo no Ensino Fundamental. Muito mais do que um dom natural percebido como parte inerente à feminilidade é a própria prática docente que os torna mais sensíveis, mais cuidadosos e mais afetuosos. No que diz respeito especificamente aos nossos professores de EF, é básico que a relação afetiva seja intensa. Saber-ensinar na presença da afetividade representa o autorreconhecimento de parte de sua competência profissional.

Atrelado à função socializadora que seria específica da disciplina EF e que nos vai sendo revelada como central para o reconhecimento da legitimidade pedagógica não somente da EF, mas das competências e habilidades pedagógicas de seus professores, aparece também, de forma recorrente nos discursos desses professores, que essa disciplina seria dotada de determinadas características que a habilitariam para o desenvolvimento da sociabilidade dos alunos. Vejamos estes relatos:

Eu acredito que a disciplina Educação Física no contexto escolar seja uma das disciplinas que mais podem e mais colaboram com esse tipo de atividade. O perfil que o mercado de trabalho exige hoje das pessoas está muito envolvido com o trabalho em grupo. De ajuda nesse sentido. Outro, do estreitamento das relações deles mesmos, de conviver com o diferente, de conviver com ideia diferente, de respeitar essa ideia diferente. De compreender as ações e de respeitar essas ações, o trabalho em grupo dá muito essa possibilidade, que eu acho riquíssima nessa parte. (Prof. Mauro)

Por exemplo, se a turma tem um problema de relacionamento, vou usar o que eu tenho para lidar com isso, porque é um espaço com o qual a Educação Física tem o privilégio de trabalhar. (Prof ${ }^{\mathrm{a}}$. Márcia).

Os professores, ao relatar que a EF propiciaria um espaço para o exercício concreto de vivências relacionais, fazem-no se referenciando no que eles ouvem, veem e sentem em relação ao que se apresenta como corrente e rotineiro na forma escolar. Melhor 
dizendo, eles parecem colocar a EF como contraponto a um ensino pautado por preocupações conteudistas, do ensino verbointelectual e de relações pedagógicas marcadas por vivências formais, frias, silenciosas. Sobre esse ponto, Borges (2002), em seu estudo sobre os saberes da base profissional de docentes dos diferentes campos disciplinares de $5^{\mathrm{a}}$ a $8^{\mathrm{a}}$ séries do ensino fundamental, mostra que os conhecimentos relativos às relações interpessoais são vistos, pelos professores de EF, como um dos mais relevantes ao seu trabalho. Nessa linha, eles colocam em destaque os conhecimentos adquiridos no campo da psicologia, seja no tempo da formação inicial, seja em estudos ou cursos realizados durante o percurso da formação continuada.

Há que se ressaltar que essas representações construídas em volta da EF têm relação íntima com a especificidade do ambiente de ensino dessa disciplina. A visão de que a EF teria maiores chances para intervir mais diretamente no processo de formação geral dos alunos não pode ser descolada da materialidade de suas práticas de ensino. São representações construídas em função de suas condições ambientais próprias, do tipo de conhecimento transmitido e em função da relação desse espaço de ensino com a totalidade da vida escolar.

Parece-nos importante lembrar que o entendimento dos professores de EF, assim como dos demais agentes escolares acerca dos papéis a serem cumpridos por essa disciplina, traz consigo elementos da socialização profissional no campo da EF. Isso porque a modelação de uma carreira situa-se na confluência entre a ação dos indivíduos e as normas e os papéis que decorrem da institucionalização das ocupações, papéis esses que os indivíduos devem interiorizar e dominar para fazer parte de tais ocupações (TARDIF, 2002). Sendo assim, intuímos que o entendimento que os professores de EF têm acerca do papel a ser cumprido, ou seja, o de educar, vincula-se ao papel historicamente cumprido por ela no projeto da educação escolar moderna.

Para levantarmos as razões dessa leitura operada pelos nossos depoentes, entendemos ser importante fazer uma digressão. Ante os desafios colocados por uma nova ordem civilizatória, organizada segundo os princípios dos modos de produção capitalista, era preciso que o corpo sofresse ações e intervenções com a finalidade de se adaptar às exigências das formas sociais de organização da produção 
e da reprodução da vida. O corpo é alvo, assim, das necessidades produtivas (corpo produtivo), das necessidades sanitárias (corpo saudável), das necessidades morais (corpo deserotizado), das necessidades de adaptação e controle social (corpo dócil). Ele precisa ser objeto da educação (escolar), mesmo porque a educação corporal é a educação do comportamento, que, por sua vez, não é corporal e sim, humana. Para Grignon (1971), a EF constituiu-se numa das bases da educação profissional porque foi e é uma das bases da educação moral; a imposição de um conjunto de regras relativas ao bom uso e à boa conservação do corpo e as práticas a ela ligadas permitem, com efeito, conservar a vitalidade moral e física dos aprendizes. Educar o comportamento corporal é educar o comportamento humano (BRACHT, 1999).

Os professores, ao demarcar como foco de sua ação na escola a intervenção nos processos de educação comportamental dos discentes, parecem ter como pano de fundo do seu discurso o entendimento de que seria atribuição exclusiva da EF o papel da educação corporal e, consequentemente, o da educação dos valores e do comportamento. É central a ideia de que à EF é atribuída uma tarefa que envolve as atividades de movimento que só pode ser corporal, uma vez que é humana. No entanto, a educação do comportamento corporal, porque humano, acontece também em outras instâncias e em outras disciplinas escolares.

Mais do que o potencial da EF de interferir na melhoria das relações intersubjetivas dos alunos, preparando-os para a vida coletiva e para o trabalho grupal, pudemos constatar nos relatos outro desdobramento desta sua função socializadora. Nos seus discursos, os professores apontam que uma das facetas mais importantes da intervenção pedagógica da EF na escola seria aquela de poder oferecer uma série de eventos e atividades extracurriculares - torneios esportivos, gincanas, rústicas, jogos interescolares:

O processo educativo da Educação Física não resume só na questão da aula. Os espaços extracurriculares, e são procurados fora da aula, dão um cabedal de possibilidades imensas. Os jogos dos calouros que era a recepção dos alunos novatos, a questão da integração

Movimento, Porto Alegre, v. 16, n. 02, p. 167-191, abril/junho de 2010. 


\begin{abstract}
que efetivamente acontecia. Por exemplo, Os Jogos escolares entre os Cefets chegavam a emocionar a gente, eu pelo menos, os alunos de voleibol quando eu viajava com eles e com elas em um dado momento é algo que emociona. Acho que isso é muito amplo e essa atuação da área hoje em função desses problemas estão privando os alunos nossos disso. (Prof. Mauro)
\end{abstract}

Fica evidente que essas atividades extracurriculares são colocadas em destaque em função não somente do envolvimento prazeroso e coletivo que proporcionam, mas também porque possibilitam à EF obter maior visibilidade institucional para seus produtos pedagógicos. Os eventos esportivos são tomados como um elemento fundamental para reconhecimento acadêmico da EF dentro da escola. Em nossas observações da sala da coordenação da EF, pudemos visualizar prateleiras recheadas de troféus e placas conquistados em eventos esportivos escolares promovidos por essa área. Entre eles, destacam-se troféus adquiridos por meio da participação do CEFET-OP nos JIFETs (Jogos interescolares dos CEFETs). Eles são os símbolos materiais de parte importante do trabalho desenvolvido pela coordenação de EF.

Além disso, podemos inferir que, ao colocarem em destaque a organização dos eventos, esses professores conseguem veicular de maneira mais ampla não somente as potencialidades socializadoras da EF, mas suas próprias competências. Eles seriam assim reconhecidos como professores dotados de habilidades pedagógicas capazes de mobilizar grupos, de envolver sujeitos coletivos, de promover o congraçamento e a participação mais ampla e solidária das pessoas.

É interessante percebermos que, nos seus relatos, os professores de EF utilizam o verbo sempre no passado. Por causa de muitos problemas internos na coordenação da EF e na própria vida institucional, esse tipo de atividade foi abandonada, o que produziu certo vazio profissional. Os relatos sobre esses eventos são carregados de saudosismo de um tempo quando eles exploravam ao máximo essas possibilidades de trabalho e de como se sentiam felizes ao produzir e participar dessas atividades. O próximo relato mostra- 
nos que a não realização desses fez com que a EF perdesse espaço e reconhecimento dentro da escola:

E para nós é aquela questão da respeitabilidade mesmo. Hoje se a gente der bobeira... Se pudessem tiravam Educação Física. Porque se você fizer só o acadêmico. Se eu movimento a escola, é diferente, o peso é outro. Os jogos interclasses e intercursos, a própria corrida rústica. (Prof. Leandro).

Além de mostrarmos que essas atividades produzem dividendos importantes no sentido do reconhecimento acadêmico dentro do currículo para a EF, os professores nos explicam que elas têm o poder de fazer com que os alunos possam participar mais intensamente da vida da escola:

$\mathrm{Eu}$ acho que pela liberdade a gente consegue fazer com que os nossos alunos sejam mais ativos, ativos no ambiente escolar. Eu não estou falando ativos de fazer atividades, não, ativos no ambiente escolar. Agora, menos do que antes, porque antes como a gente fazia competições, fazia outras atividades, os alunos se envolviam muito mais, e levavam isso para fora da aula de Educação Física, levavam isso para as outras disciplinas, eles se tornavam mais ativos mesmo. Até o grêmio estudantil funcionava de forma muito mais eficaz quando nós também trabalhávamos mais na EF. Dá para fazer uma relação temporal perfeita, entre a atuação do grêmio na escola, as atividades que a gente desenvolvia, e hoje como é a atividade do grêmio e atividades que a gente não desenvolve, e como o grêmio ficou. Porque antes a gente movimentava, colocávamos o grêmio junto conosco e os alunos se envolviam. (Prof ${ }^{a}$. Márcia).

Nesse relato, podemos verificar que é atribuída à EF a tarefa de tentar aproximar os atores escolares e os seus múltiplos setores funcionais. Nesse sentido, podemos inferir que os professores de EF colocam sua disciplina como elemento facilitador da recepção de uma boa aprendizagem. Fazer com que os alunos se tornem 
mais ativos no ambiente escolar, levando o que eles aprendem nesses eventos para as outras disciplinas, faria com que eles tivessem inserção mais rica e produtiva no interior da vida escolar.

Os professores, quando falam da positividade dos alunos de viver mais intensamente a escola e os professores, remetem-se ao potencial socializador da EF. Mostram que as vivências relacionais são objetos centrais de sua intervenção pedagógica na escola, ocupando, com isso, lugar de destaque na hierarquia dos conteúdos de sua docência.

Ademais, ao lembrarem da positividade do exercício da vivência coletiva e grupal no interior da escola, esses professores mostram-se atentos à totalidade da vida escolar. Além de reafirmar que a sua intervenção pedagógica não se limita ao ensino de conteúdos, eles nos parecem revelar que a sua prática pedagógica é pensada em função da sua repercussão dentro da vida escolar. As aprendizagens vividas na EF têm valor cultural medido em função da possibilidade de sua utilização, por parte dos alunos, ainda no próprio universo da escola. As aprendizagens ali vividas devem ser consumidas não somente no futuro distante, que ocorrerá fora da escola, mas também no imediato da vida escolar na qual brotam experiências ricas de relações humanas, de sentimentos, de modos de ver e de sentir o mundo. O pensamento e as ações de nossos professores de EF talvez estejam referenciados no âmbito do estabelecimento de ensino, predominantemente.

Tal questão pode ser interpretada nos relatos dos professores, quando são indagados sobre as especificidades da prática pedagógica da EF. Suas respostas demonstram que um dos papéis de tal disciplina seria aquele de oferecer vivências e atividades de ensino que pudessem produzir a sensação de esquecimento do que seria corrente dentro das salas de aula, operando uma compensação do desgaste provocado pelas atividades tidas como mais sérias ou acadêmicas. Vejamos o que eles nos dizem:

É um espaço livre para expressar corporalmente. Justamente, dentro da formalidade escolar ela é mais informal. Então ali seria até o contraponto, nós identificamos, lá em baixo lazer, em cima trabalho. (Prof. Leandro). 
É essa liberdade que a gente pode dar ao aluno que os outros professores ainda não descobriram que eles também podem. A nossa liberdade ao aluno é mais explícita. Muitos professores também poderiam fazer isso, mas acho que eles não descobriram ainda. Não sei se eu no lugar deles teria descoberto, e para nós isso já veio pronto, o que é um privilégio. (Prof ${ }^{a}$. Márcia).

Há um sentimento por parte deles de que caberia à EF a função de oferecer aos alunos vivências muito parecidas ao que se atribui aos momentos de lazer em nossa vida cotidiana. Primeiro, a EF seria vista como espaço produtor de experiências de caráter compensatório, na medida em que colaboraria para compensar o desgaste provocado pelo trabalho intelectual na sala de aula. A EF teria assim caráter utilitarista, porque uma de suas funções seria a de recuperar e a de preparar os alunos para o trabalho, ou melhor, para as atividades de ensino vistas como mais formais e sérias.

Atrelada a essa primeira função, aparece aquela na qual o universo do lazer seria o local mais propício para experiências de gratuidade, de fruição e de produção cultural. Experiências que, segundo os relatos desses docentes, não parecem ser muito próprias das disciplinas consideradas mais acadêmicas. Parece existir o reconhecimento de que tais disciplinas seriam marcadas pela formalidade das relações, pela estandardização do comportamento, pela tensão das cobranças por rendimento escolar e pela inibição das experiências de cunho mais estético.

Nessa perspectiva, é interessante percebermos que, ao construírem argumentos que expliquem os caminhos pelos quais a EF se legitima na escola, os professores o fazem por um viés não acadêmico. Seguram-se nas possibilidades que essa disciplina teria de oferecer aos alunos experiências de ensino contrárias ou diferentes do que seria corrente na vida escolar. Inferimos de tal conclusão que a EF e, consequentemente, seus professores, conseguem reconhecimento profissional dentro da escola veiculando práticas e experiências pedagógicas marcadas por uma lógica própria. A legitimidade pedagógica da EF e dos saberes profissionais de seus docentes dá-se mediante a participação de ações comuns por meio de pactos divergentes. 
Novamente, a EF é deslocada do rol das disciplinas acadêmicas para um campo de atividades que seriam destinadas à recepção de uma boa aprendizagem. Quando os professores nos relatam que a EF teria como uma de suas funções a de se constituir num espaço de lazer, eles talvez queiram dizer que as experiências educativas proporcionadas por ela se apresentam como suporte ou apoio para as atividades de ensino tipicamente academicas. Neste relato, o Prof. Mauro nos esclarece melhor:

Os tempos acadêmicos da sala de aula exigem um tempo de concentração imenso do aluno, a necessidade de atenção muito grande e isso inibe, o inibe muito de falar, de conversar de se expressar, e a nossa organização acadêmica é nesse sentido, então acho que a Educação Física quebra completamente isso, a nossa sala de aula não tem carteira, pode ter, mas não tem na sua essência, quebra completamente isso, e acho que isso para o contexto acadêmico é fundamental. Entendo a EF como um grande suporte, de ajuda, não que esteja à parte, ele está contextualizado, está junto, mas para que o aluno tenha êxito na sua parte acadêmica também. (Prof. Mauro)

\section{CoNSIDERAÇõES FINAIS}

Nos relatos disponibilizados pelos professores de EF, pudemos identificar e interpretar algumas das características dos objetos-condições de ensino que são constitutivas das singularidades que demarcam a prática docente em EF dentro do CEFET-OP.

Num ambiente onde as práticas de ensino são marcadas pela tensão provocada pelas exigências de desempenho escolar, pela formalidade das relações de ensino, pelo individualismo pedagógico, pelo ensino verbointelectual, pelo conteudismo dos processos de ensino, pela necessidade de formar para o mundo do trabalho, pelo caráter propedêutico do ensino, de trazer as marcas de uma escola de tempo integral, a EF acaba por absorver sentidos e significados muito próprios. Ela deve ser a disciplina que $e d u c a$, que possibilita vivências de sociabilidade, que promove o encontro e o congraçamento de 
uma escola partida e fragmentada, que oferece abertura para vivência de catarse por meio de atividades muito próximas às vividas no mundo do lazer. Além disso, mas em grau menor, ela deve cumprir o papel de instruir.

O que se pôde perceber, portanto, é que não há como separar o processo de construção dos saberes da base profissional desses docentes da escola como totalidade. $\mathrm{O}$ efeito estabelecimento de ensino mostrou-se importante, não apenas no processo de formação dos alunos, mas também no de formação dos professores. Os fatores endógenos que caracterizam o efeito estabelecimento, onde processamse estilos particulares de organização pedagógica, modos de regulação sociais específicos e de mobilização de seus atores de utilizar recursos próprios, são significativos ao processo de constituição de identidade profissional desses docentes. Entre as características que constituem essa identidade profissional, chamou-nos a atenção o fato de os professores pesquisados possuírem uma visão bastante positiva do magistério em EF, diferentemente do que tem sido apontado por pesquisas desenvolvidas nesse campo (JEBER, 1996).

Assim, as reflexões contidas no nosso trabalho apontam para a consideração da escola como objeto de estudo, ao permitir outra visibilidade da dimensão formativa presente na diversidade dos contextos educacionais e nas situações de trabalho que neles emergem. Essa visão do estabelecimento de ensino (EE) como um contexto globalmente formativo para o conjunto dos seus habitantes abre a possibilidade de superar teoricamente a dissociação, tendencial, entre a educação das crianças e a educação dos adultos. Os processos de formação de adultos (professores) e crianças (alunos) aparecem referidos, no caso do estabelecimento de ensino, a um mesmo espaço organizacional, a um mesmo tempo (aprendizagens por interações recíprocas), aos mesmos princípios (CANÁRIO, 1996).

Atrelada a essa problemática, pudemos constatar certa incongruência entre o que a nossa pesquisa destaca e o que a teoria anuncia como características do que seja o modus operandi da atuação de docentes do Ensino Médio. Alguns estudos vêm momostrando a existência de uma cultura docente particular desses 
profissionais, imputam a eles o desinteresse pelas questões "extramuros" da sala de aula e do campo disciplinar ao qual pertencem (DEROUET, 1995; CANÁRIO, 1996). Nossa pesquisa vem relativizar essa afirmação. Os professores de EF pesquisados, em que pese a eles trabalharem numa escola de nível médio, buscam outras referências para organizar sua intervenção pedagógica. Entre elas, podemos citar a trama temporal da vida escolar, o que eles entendem ser as demandas imediatas dos alunos no cotidiano de vida da instituição e o apoio às atividades de ensino. Buscam promover aprendizagens não formalizadas no currículo real, a saber: a integração entre os alunos, a cooperação e a produção de um sentimento de "corpo institucional" no interior da escola.

Essa sensibilidade demonstrada pelos professores de EF de pensar sua prática articulada à totalidade da escola pode ser atribuída, em parte, à especificidade pedagógica do objeto de ensino da EF e os múltiplos sentidos e significados mobilizados pela escola, pelos alunos e pelos próprios professores de EF no cotidiano sociocultural da escola.

Os conteúdos de ensino da EF e as condições ambientais da sala de aula da EF parecem ter a capacidade de projetar e ligar o ensino da EF e os seus professores na direção de proposições e problemas mais diretamente relacionados ao mundo cotidiano da escola, à sua cultura ou a uma escola que existe dentro de outra escola. Esta outra escola, entendida não como instituição que apenas transmite conhecimentos disciplinares, mas como meio de vida social. Sobre esse ponto, Perrenoud (2000) lembra que a noção de práticas sociais de referência (práticas profissionais, práticas de comunicação e de sociabilidade) permitiria às disciplinas, como a EF, a educação artística e a educação das línguas, denominar que aquilo a que elas se referem não é redutível aos savoir savants. Para o referido autor, todas as disciplinas podem contribuir para a formação geral dos estudantes, mas algumas são orientadas explicitamente para esse objetivo.

Ligadas a essa questão, as análises anunciadas em nosso estudo, de certa forma, relativizam conclusões de outras pesquisas que salientam 
que o caráter "maternal" ou afetivo do ensino estaria mais presente em escolas de ensino fundamental ou restrito ao universo de atuação docente feminina (LESSARD et al., 2003). Nossos dados revelaram que, em função do tipo de representação produzida na escola ao redor da EF, da especificidade do seu objeto de ensino e das condições ambientais nas quais o ensino se materializa, a cultura do cuidado não se apresenta em contraposição às dimensões da instrução. Ao contrário, ela é um componente importante no processo de elaboração das práticas de instrução dos professores. A noção de profissionalismo não aparece descolada dos aspectos afetivos do exercício da docência, mas colocada numa posição de relevo em relação aos aspectos técnicos. Mais do que isso, a cultura do cuidado surge como um componente positivo que harmoniza a identidade profissional desses docentes.

Dessa forma, as habilidades pedagógicas demonstradas pelos nossos professores e colocadas em prática ao enfrentamento dos desafios de seu trabalho não podem ser desvinculadas do conhecimento que eles têm da disciplina que ensinam na escola. Seus saberes pedagógicos têm íntima relação com tudo o que envolve esse contexto de ensino situado. Esses saberes são laborados na relação pedagógica que os professores estabelecem com o conteúdo de ensino e o que o ensino com e nesse componente curricular possibilita de medições com os alunos, a escola e a educação em geral. São saberes que se edificam em meio a esse contexto de ensino, mas que não se restringem aos conhecimentos disciplinares.

Esses professores são vistos e se veem como profissionais dotados de habilidades e competências pedagógicas que os capacitariam para um trabalho diferenciado dentro da escola. Educar para a vida, educar para o mundo do trabalho, intervir na formação geral dos alunos, melhorar a relação intersubjetiva dos discentes, interferir na melhoria das relações humanas no interior da vida institucional e oferecer experiências próximas àquelas vividas nos momentos de lazer seriam funções que caberiam à EF e aos seus profissionais. São expressões, portanto, das situações de ensino singulares que demandam o desenvolvimento de saberes pedagógicos que seriam próprios dos professores de EF e expressão pública da própria capacidade de ensinar. 


Models of professional action of Physical
Education professors of a professionalizing
school
Abstract: The work tells some of the results of a study
carried through with professors of Physical Education
of a Professionalizing School. More specifically, it turns
on the set of the perceptions that professors of Physical
Education of a Professionalizing School have on its
teaching work in the school, from models of the
professional action, built inside a specific discipline field:
the Physical Education. It concludes showing that the
pedagogical practice in PE detains a singular nature, a
producing nature of a set of singular representations
concerning the paper of the Physical Education and of
its professors, representations these that serve to de-
fine, to structuralize and to guide the performance of
these professors in action situations.
Keywords: Physical Education. Faculty. Professional
practice.

Modelos de la accion profisional de profesores de Educacíon Física de una escuela de la ensenanza profisional

Resúmen: El trabajo relata algunos de los resultados de un estudio ejecutado con profesores de Educación Física de una escuela de la enseñanza profesional. Más específicamente, versa acerca del sistema de las opiniones que los profesores de Educación Física de una escuela de la enseñanza profesional tienen en su trabajo de la enseñanza en la escuela, de los modelos de la acción profesional, construidos dentro de un campo disciplinar específico: la educación física. Concluye, demostrando que la práctica pedagógica en EF en la escuela ostenta una naturaleza singular, produciendo la naturaleza de un sistema de representaciones singulares referentes al papel de la educación física y de sus profesores, las representaciones éstos que sirvan definir, estructurar y dirigir el funcionamiento de estos profesores en situaciones de la acción.

Palabras clave: Educación Física. Docentes. Práctica Profesional

\section{REFERÊNCIAS}

BORGES, Cecília Maria Ferreira. 0 professor da educação básica de $5^{\mathbf{a}}$ a $8^{\mathrm{a}}$ série e seus saberes profissionais. 2002. Tese (Doutorado em Educação) Faculdade de Educação, Pontifícia Universidade Católica do Rio de Janeiro, Rio de Janeiro, 2002. 
Diferentes tipologias e classificações de um campo de pesquisa.

Educação e Sociedade/Revista quadrimestral de Ciência da Educação/ CEDES, v. 22, n. 74, p. 59-76, abr. 2001.

BRACHT, Valter. A constituição das teorias pedagógicas da Educação Física. Cadernos CEDES, Campinas, SP, v. 19, n. 48, p. 69-88, ago. 1999.

CANÁRIO, Rui. O estudo sobre a escola: problemas e perspectivas. In: BARROSO, João (Org.). O estudo da escola. Porto: Porto Editora, 1996.

CARVALHO, Marília Pinto de. Gênero e trabalho docente: em busca de um referencial teórico. In: BRUSCHINI, Cristina; BUARQUE DE HOLLANDA, Heloísa (Org.). Horizontes plurais: novos estudos de gênero no Brasil. São Paulo: FCC, 1998.

CHERVEL, André. História das disciplinas escolares: reflexões sobre um campo de pesquisa. Educação e Realidade, Porto Alegre, n. 2, p.177-229, 1998.

DEROUET, Jean-Louis. O funcionamento dos estabelecimentos de ensino em França: um objeto científico em redefinição. In: BARROSO, João (Org.). 0 estudo da escola. Porto: Porto Editora, p 61-86, 1996.

DEVALY, M. Savoirs scolaires et didatique dês discipline: une encyclopédie pour aujourd'hui. Paris: ESF Editeur, 1995.

GAUTHIER, Clemont. Por uma teoria da Pedagogia. Ijuí: Editora UNIJUÍ, 1998.

GRIGNON, Claude. L'Ordre das choses (les fonctions sociales de L'enseignement technique). Paris: Les Editions de Minuit, 1971.

HUBERMAN, Michael. O ciclo de vida profissional dos professores. In: NÓVOA, António (Org.). Vida de professores. Porto: Porto Editora, p 31-62, 1992.

JEBER, Leonardo José. A educação física no ensino fundamental: o lugar ocupado na hierarquia dos saberes escolares. 1996. Dissertação (Mestrado em Educação) - Faculdade de Educação, Universidade Federal de Minas Gerais, Belo Horizonte, 1996.

LESSARD, Claude; TARDIF, Maurice. Les identities enseignantes: analyse de facteurs de différenciation du corps enseignant québécois 1960 - 1990. Montreal Editions du CRP, Université de Sherbrooke, 2003.

SHULMAN, L. L. Those who understand: knowledge growth in teaching. Educacional Researcher, Washington, v. 15, n. 2, p. 4-14, feb. 1986.

SHULMAN, L. L. Knowledge and teaching: foundations of the new reform. Harvard Educational Review, v. 57, n. 1, p. 1-22, feb. 1987

TARDIF, M. Os professores enquanto sujeitos do conhecimento: subjetividade, prática e saberes no magistério. In: CANDAU, Vera. Didática, Currículo e Saberes escolares. Rio de Janeiro: DP\&A, 2000. 
Modelos de ação profissional de professores de Educação Física...

Saberes docentes e formação profissional. Petrópolis, RJ: Vozes, 2002.

Recebido em: 27.05.2009

Aprovado em: 18.04.2010

Financiamento: CAPES

Movimento, Porto Alegre, v. 16, n. 02, p. 165-191,abril/junho de 2010. 